01;03

\title{
Вытеснение нефти из пористой среды С использованием графитовой суспензии
}

\author{
() Ю.В. Пахаруков ${ }^{1,2}$, Ф.К. Шабиев ${ }^{1,2, \uparrow, ~ Р . Ф . ~ С а ф р а р г а л и е в ~}{ }^{2}$ \\ ${ }^{1}$ Тюменский индустриальный университет, Тюмень, Россия \\ ${ }^{2}$ Тюменский государственный университет, Тюмень, Россия \\ ๑E-mail: faridshab@mail.ru:
}

Поступило в Редакцию 3 июля 2017 г.

Обнаружено, что водная графитовая суспензия из планарных наноструктур на границе раздела нефть-вода обладает вытесняющей способностью. В эксперименте с использованием ячейки Хеле-Шоу показано, что в процессе вытеснения на границе раздела не образуются вязкие пальцы, являющиеся результатом неустойчивости на границе раздела нефть-вода.

DOI: 10.21883/PJTF.2018.04.45632.16943

В настоящее время бо́льшая часть нефтяных месторождений переходит на заключительную стадию разработки [1]. В связи с этим задача полноты вытеснения нефти из пласта решается с применением физико-химических методов воздействия на пласт совместно с его заводнением [2]. Существует ряд представлений о механимах действия внутри пластовых оторочек на основе водных растворов поверхностноактивных веществ (ПАВ), полимеров, щелочно-кислотной обработки и т.д. [3]. Принято считать, что наиболее эффективным является микоэмульсионное заводнение. Но для этого заводняющий агент должен обладасть необходимой подвижностью и ультранизким поверхностным натяжением на границе с нефтью. В этом случае граница раздела нефть-вода будет устойчивой и не будут образовываться вязкие пальцы прорыва воды через слой нефти. 
Однако микроэмульсии представляют собой сложную динамическую структуру и очень чувствительны к катионам высокой валентности, содержащимся в пласте. С повышением температуры и давления смещается фазовое равновесие и увеличивается влияние стенок капилляров, а движение в пористом коллекторе с фрактальной геометрией приводит к стохастическому воздействию на микроэмульсию. В результате устойчивое в лабораторных условиях микроэмульсионное состояние становится неустойчивым в условиях реального пласта [2]. В связи с этим возникает вопрос: можно ли создать на границе раздела нефть-вода переходную область с низким поверхностным натяжением, не являющуюся микроэмульсией, обладающей слабой чувствительностью к температуре и жесткостью пластовых вод?

Задачей настоящей работы является исследование вытесняющей способности воды при добавлении графитовых наночастиц на границу раздела нефть-вода.

Известно, что низкое поверхностное натяжение на границе раздела нефть-вода связывается с образованием структуры из жидкокристаллических монослоев макромолекул [2]. Такие слои могут быть образованы из планарных наночастиц графита с размером менее $400 \mathrm{~nm}$. При этом стабильность суспензии будет обеспечиваться условием [4]

$$
\Delta G_{m i x}=\Delta H_{m i x}-T \Delta S \leqslant 0,
$$

где $\Delta S$ - изменение энтропии, $\Delta H_{m i x}$ - изменение энтальпии смеси, $\Delta G_{m i x}$ - изменение энергии Гиббса смеси.

Следовательно, растворитель должен иметь удельную поверхностную энергию $(\sigma)$, близкую к энергии монослоя из графитовых частиц. Таким свойством обладает водный раствор этанола [5]. Изменением концентрации этанола можно подобрать $\sigma$, близкую к плоским частицам графита.

В реальных условиях очень часто наблюдается напластывание жидкостей (движение нефти в воде). В этом случае решение задачи движения возможного контакта зависит от коэффициента пропорциональности мощности пласта и угла наклона пласта.

На форму водонефтяного контакта влияет соотношение коэффициента вязкости нефти и воды. Образование переходных областей приводит к уменьшению скорости движения по подошве пласта и увеличению скорости по кровле пласта. Разная скорость внутреннего и

Письма в ЖТФ, 2018, том 44, вып. 4 


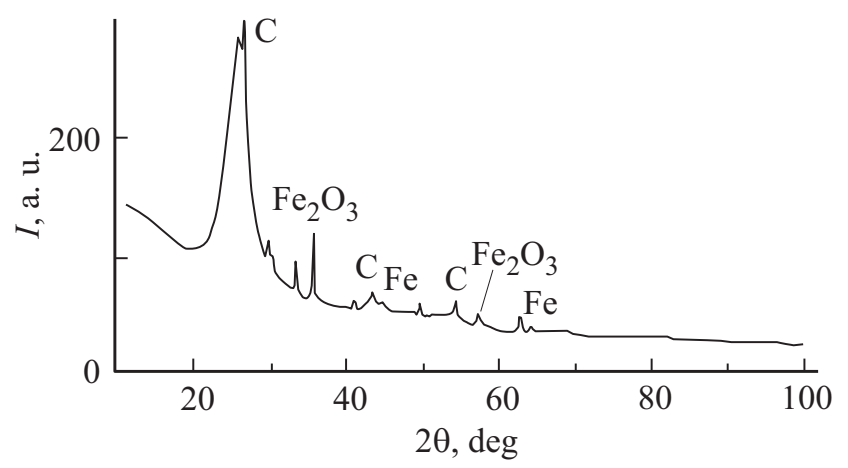

Рис. 1. Рентгенограмма углеродного материала, содержащего графитовые планарные структуры, полученного в результате взаимодействия пористого углерода, нагретого до $1000^{\circ} \mathrm{C}$, с дистиллированной водой.

внешнего контуров зависит от проницаемости породы. Даже в простых схемах вытеснения наблюдается искажение формы водонефтяного контура с образованием языков обводнения. Коэффициентом устойчивости служит величина коэффициента подвижности

$$
\lambda=\frac{k_{w o} \mu_{o i l}}{k_{o w} \mu_{B}},
$$

где $k_{w o}$ - проницаемость по воде в присутствии остаточной нефти, $k_{o w}-$ проницаемость по нефти в присутствии связанной воды, $\mu_{o i l}-$ вязкость нефти, $\mu_{B}-$ вязкость раствора.

Фронт устойчив для $\lambda<1$, т.е. величина $\mu_{B}$ не должна сильно увеличиваться. Следовательно, суспензия из графитовых (планарных) частиц должна обладать малым поверхностным натяжением $\sigma$ на границе раздела нефть-вода, а вязкость раствора $\mu_{B}$ и его плотность $\rho$ должны удовлетворять эмпирическому условию

$$
0.1 \geqslant \frac{\mu_{B}}{\sqrt{\sigma \rho d}}
$$

где $d-$ средний размер пор в пористой структуре (или диаметр капилляра),

$$
k_{\text {ow }} \mu_{B}<k_{w o} \mu_{\text {oil }} \text {. }
$$

Письма в ЖТФ, 2018, том 44, вып. 4 


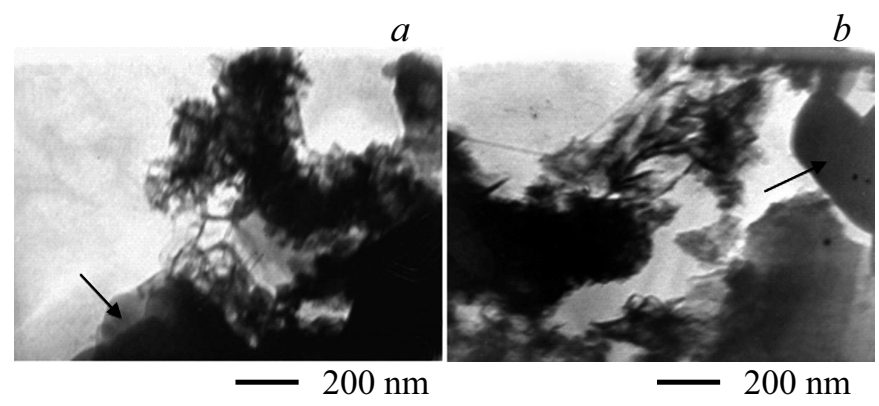

Рис. 2. Электронно-микроскопические изображения углеродного материала, полученного в результате охлаждения в дистиллированной воде поликристаллического графита, нагретого до $1000^{\circ} \mathrm{C}$. Стрелкой указана область, содержащая совершенные кристаллы графита - планарные наночастицы: $a-$ толщина кристаллита много меньше его диаметра, $b$ - толщина кристаллита соразмерна его диаметру.

Образцы графитовых планарных наноструктур были синтезированы по методике, предложенной в работе [6]. Порошкообразный поликристаллический графит нагревался в печи Таммана до $1000^{\circ} \mathrm{C}$, затем образцы извлекались из печи и опускались в сосуд с дистиллированной водой комнатной температуры $\left(\sim 20^{\circ} \mathrm{C}\right)$. В результате взаимодействия нагретого поликристаллического графита с холодной водой часть графита выпадала в осадок, другая его часть оставалась на поверхности воды, образуя тонкую пленку, которая затем извлекалась. Далее извлеченную пленку растворяли в $70 \%$ растворе этанола, получая эмульсию.

При анализе рентгенограммы углеродного материала, полученной на рентгеновском дифрактометре ДРОН-3 ( $\mathrm{Cu} K_{\alpha}$-излучение), были идентифицированы дифракционные максимумы, соответствующие графиту, турбостратному углероду, чистому железу и трем модификациям оксида железа $\left(\mathrm{Fe}_{2} \mathrm{O}_{3}(10 R), \mathrm{Fe}_{2} \mathrm{O}_{3}(100 M), \gamma-\mathrm{Fe}_{2} \mathrm{O}_{3}\right)$ (рис. 1).

Электронно-микроскопические исследования графитового материала, выполненные на просвечивающем электронном микроскопе УЭМВ-100К по стандартным методикам, показали наличие идеальных кристаллов графита различной толщины (рис. 2).

Письма в ЖТФ, 2018, том 44, вып. 4 


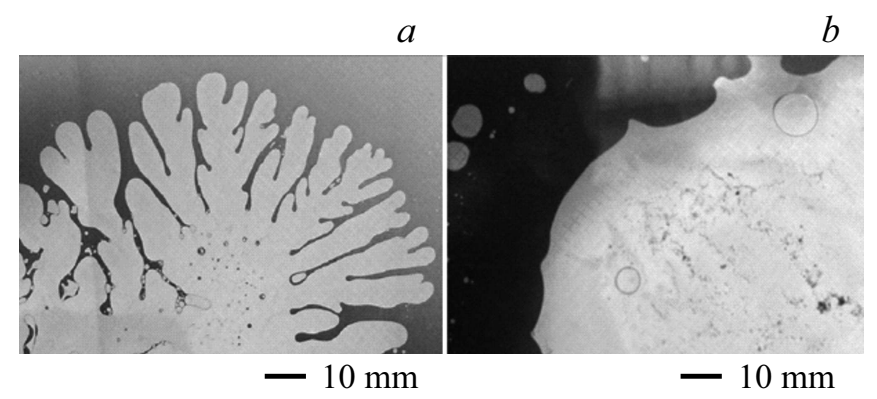

Рис. 3. Вытеснение водой нефти в ячейке Хеле-Шоу: $a-$ с образованием вязких пальцев, $b-$ без образования вязких пальцев с устойчивой границей раздела вода-графит-нефть.

Для исследования поведения границы раздела вода-нефть в работе была использована радиальная ячейка Хеле-Шоу, геометрические параметры которой составляли $R_{0}=2 \mathrm{~mm}, R_{\infty}=120 \mathrm{~mm}, b=0.6 \mathrm{~mm}[7,8]$.

В результате синтеза планарных углеродных наночастиц сформировалась суспензия с размером частиц 200-400 nm с низким поверхностным натяжением $\sigma=43 \mathrm{mN} / \mathrm{m}$.

Добавление суспензии в нефтяную фазу уменьшило исходную вязкость на $0.7 \%$, что усилило условие устойчивости фронта (коэффициент подвижности $\lambda<1)$.

При нагнетании воды без планарных частиц графитовой суспензии в ячейку Хеле-Шоу (с постоянным давлением $p=10 \mathrm{kPa}$ ) образовывались вязкие пальцы вследствие неустойчивости границы раздела, свидетельствующие о прорыве воды сквозь нефть (рис. 3, $a$ ). При добавлении в воду графитовых наночастиц вытеснение идет устойчивым фронтом без образования вязких пальцев при том же режиме с постоянным давлением $p=10 \mathrm{kPa}$. На рис. $3, b$ отчетливо видна граница раздела нефть-суспензия-вода.

Итак, суспензия формирует устойчивую границу раздела нефть-вода даже без добавления ПАВ.

Для усиления эффекта устойчивости в дальнейшем можно, комбинируя ПАВ и этанол в суспензии из графитовых планарных наночастиц, значительно снизить поверхностное натяжение.

Письма в ЖТФ, 2018, том 44, вып. 4 
Таким образом, результаты исследования указывают на перспективность разработки технологии по вытеснению остаточной нефти из нефтегазового пласта с использованием суспензии на основе графита.

\section{Список литературы}

[1] Химические методы в процессах добычи нефти / Отв. ред. Н.М. Эмануэль, Г.Е. Заиков. М.: Наука, 1987. 238 с.

[2] Микроэмульсии. Структура и динамика / Под ред. С.Е. Фриберга, П. Ботореля. М.: Мир, 1990. 320 с.

[3] Хавкин А.Я. Гидродинамические основы разработки залежей нефти с низкопроницаемыми коллекторами. М: МО МАНПО, 2000. 525 с.

[4] Антонова И.В. // УФН. 2017. Т. 187. № 2. С. 220-234.

[5] Соотс Р.А., Якимчук Е.А., Небогатикова Н.А., Котин И.А., Антонова И.В. // Письма в ЖТФ. 2016. Т. 42. В. 8. С. 102-110.

[6] Belenkov E.A., Shabiev F.K. // Письма о материалах. 2015. Т. 5. № 4. C. $459-462$.

[7] Мартюшев Л.М., Бирзина А.И. // Письма в ЖЭТФ. 2014. Т. 99. В. 8. C. $516-522$.

[8] Мартюшев Л.М., Бирзина А.И. // Письма в ЖТФ. 2008. Т. 34. В. 5. С. 71-78. 